\title{
MOVIMIENTOS SOCIALES Y RECURSOS NATURALES EN AMÉRICA LATINA: resistencias al neoliberalismo, configuración de alternativas*
}

\author{
José Seoane**
}

\begin{abstract}
Resumen: La implantación del modelo neoliberal en América Latina y el Caribe así como la reciente recuperación del crecimiento económico a nivel regional reposan fundamentalmente en la explotación intensiva de los recursos naturales, orientada a la exportación y, en gran medida, bajo control del capital trasnacional. Frente a ello emergieron y se desarrollaron en el continente un número creciente de conflictos, movimientos sociales y convergencias sociopolíticas a nivel local, nacional y regional. Estas experiencias se enmarcan en el nuevo ciclo de protesta social abierto en la segunda mitad de la década de los '90, y en ellas pueden vislumbrarse las principales características que distinguen la configuración actual de la acción y organización colectiva de los movimientos sociales contemporáneos. La defensa del carácter de bienes comunes de los recursos naturales se ha expresado en la confrontación social contra las devastadoras consecuencias medioambientales, la destrucción del hábitat y el desplazamiento forzoso de poblaciones. Así también ha tomado cuerpo en los cuestionamientos de los efectos y el modelo de apropiación privada de estos recursos y de los beneficios derivados de su explotación. La articulación de estos procesos ha significado en el terreno de los movimientos sociales la vinculación
\end{abstract}

\footnotetext{
Este artículo retoma un conjunto de elaboraciones colectivas resultado de la labor desarrollada en el marco del Programa del Observatorio Social de América Latina (OSAL) del Consejo Latinoamericano de Ciencias Sociales (CLACSO). Agradezco especialmente a Clara Algranati por sus sugerencias y comentarios así como también a Emilio Taddei y todo el equipo del Programa.

** Sociólogo, Coordinador del Observatorio Social de América Latina (OSAL) del Consejo Latinoamericano de Ciencias Sociales (CLACSO) y profesor de la Facultad de Ciencias Sociales de la Universidad de Buenos Aires (UBA, Argentina).
}

Artigo recebido em 5 mar. 2006 e aprovado em 13 maio 2006. 
del ciclo de resistencias con la construcción de alternativas y la postulación de horizontes emancipatorios.

Palabras clave: movimientos sociales, conflictos, protestas sociales, recursos naturales, neoliberalismo.

Los pueblos de la América latina y caribeña habitan un territorio en el que crecen el $25 \%$ de los bosques y el $40 \%$ de la biodiversidad del globo. Casi un tercio de las reservas mundiales de cobre, bauxita y plata son parte de sus riquezas, y guarda en sus entrañas el $27 \%$ del carbón, el 24\% del petróleo, el $8 \%$ del gas y el 5\% del uranio. Y sus cuencas acuíferas contienen el $35 \%$ de la potencia hidroenergética mundial, contando - desde la selva chiapaneca a la amazonía - con una de las reservas de biodiversidad más importantes del planeta.

La extensión de las contrarreformas neoliberales a toda la región durante la década de los noventa, las más recientes olas de libre comercio con las iniciativas de control militar y gobernabilidad sistémica que las acompañan y el incremento de la demanda del mercado mundial durante el último año hicieron de la explotación de estos recursos naturales (intensiva, orientada a la exportación y, en gran parte, bajo control del capital transnacional) una de las fuerzas centrales de la recuperación del crecimiento económico regional.

Por otra parte, frente a sus devastadoras consecuencias sobre el medio ambiente y el hábitat de pueblos y comunidades enteras, y a la apropiación privada de esas riquezas y de los beneficios resultado de su explotación, un sinnúmero de movimientos sociales, coordinaciones, conflictos y resistencias se han desplegado en los últimos años en toda la región construyendo alternativas y promoviendo horizontes emancipatorios. El presente artículo, intenta presentar un panorama de estas experiencias en Latinoamérica, particularmente alrededor de algunos de los hechos acaecidos a lo largo del 2005. Se inicia con un breve análisis de las características que presenta la conflictividad social a nivel regional en la última década y las nuevas configuraciones que parecen signar las prácticas de los movimientos sociales que la protagonizan. 


\section{Un nuevo ciclo de conflicto social}

Los años '90 abrieron paso a una renovada mundialización capitalista en su forma neoliberal cuyo impacto en América Latina ha sido por demás notorio y profundo. Prolongando un proceso iniciado en las décadas anteriores, auspiciado por el llamado "Consenso de Washington", la adopción de las políticas neoliberales hubo de generalizarse en toda la región para asumir una nueva radicalidad. La aplicación de estas políticas enfrentó ciertamente numerosas resistencias y protestas aunque las mismas resultaron en la mayoría de los casos incapaces de obstaculizar su implementación. Sin embargo, desde mediados de dicha década la realidad social latinoamericana apareció nuevamente y de manera creciente signada por el incremento sostenido de la conflictividad social. En algunos casos se ha señalado como acontecimiento emblemático del despertar de este ciclo al levantamiento zapatista de principios de 1994 así como al ciclo de movilizaciones - particularmente indígenas - que conllevó la caída del gobierno de Abdalá Bucaram en Ecuador (1997). Ambos procesos apuntan ya sobre el especial protagonismo que habrán de tener los movimientos indígenas en la contestación social regional a las políticas neoliberales. Una muestra de dicho incremento de la protesta social puede apreciarse a partir de los datos suministrados por el OSAL (Observatorio Social de América Latina, CLACSO) que, sobre la base de un seguimiento del conflicto en diecinueve países de la región, ${ }^{1}$ refieren un significativo aumento de los mismos entre 2000 y 2002 (más que se duplican), para oscilar a partir de dicho año hasta 2005, casi sin excepciones, en una franja de 2.100 a 2.400 hechos de conflicto (OSAL, 2005) así como los mismos, para dicho período, se concentran particularmente en la región andina (aproximadamente el 40\%) distribuyéndose en tercios entre el Cono Sur y el área conformada por México, Centroamérica y el Caribe.

Por la magnitud regional que alcanza - más allá de las excepciones y diferencias nacionales -, por las características que presenta y por su perdurabilidad, este incremento de la conflictividad social da cuenta de la aparición de un nuevo ciclo de protesta social, que inscribiéndose en el campo de fuerzas resultante de las regresivas 
transformaciones estructurales forjadas por la implantación del neoliberalismo en nuestros países, emerge en contestación a éstas.

Este proceso de crecimiento del conflicto y emergencia de movimientos sociales, en el marco de la crisis económica que atravesó a la mayor parte de la región (y no solamente a ella) desde fines de la década de los '90 y frente a los intentos de profundizar las políticas neoliberales, se tradujo en algunos casos en "levantamientos populares" (que concluyeron, la más de las veces, con la caída de gobiernos), en la constitución de "mayorías electorales" críticas al neoliberalismo e incluso en la reaparición de una discursividad política que se diferencia del mismo. En su diversidad, estos hechos marcaron, en muchos de los países de la región, la apertura de una profunda crisis de legitimidad que cuestiona al régimen neoliberal forjado en las décadas precedentes.

\section{La nueva configuración de los movimientos sociales}

El nuevo ciclo de protestas que cobra impulso desde mediados de la década del ' 90 y los movimientos sociales que lo protagonizan presentan características distintivas que los diferencian de aquellos que signaron el escenario de la contestación social en décadas pasadas. El primer hecho evidente nos indica que la mayoría de las organizaciones sociales que promueven estas protestas han surgido o sido refundadas en las dos últimas décadas. Pero no se trata sólo de una cuestión que remite exclusivamente a la vida o historia organizacional de estos movimientos sino particularmente a la configuración que éstos asumen.

Ciertamente el análisis de estas experiencias y, particularmente, el entendimiento y conceptualización de las novedades que dichos movimientos plantean en el decurso histórico de la acción colectiva y la contestación social constituyen uno de los centros de atención de la elaboración y revitalización del pensamiento social latinoamericano actual. No es en este caso la intención el presentar los ejes problemáticos alrededor de los cuales se orientan estos debates, sino 
la de reseñar brevemente algunas de las características que, a nuestro entender, distinguen la configuración de los movimientos sociales en la actualidad y sobre las que hemos profundizado en ocasiones anteriores (Seoane, Taddei y Algranati, 2005).

Movimientos sociales de base territorial tanto en el mundo rural como también en el espacio urbano han emergido en el escenario latinoamericano constituyéndose en algunos casos, en relación a su identidad étnico-cultural (los movimientos indígenas), en referencia a su carencia (los sin tierra, sin techo o sin trabajo) o en relación a su hábitat de vida compartido (por ejemplo los movimientos de pobladores). La emergencia de poderosos y arragaidos movimientos indígenas y campesinos que alcanzan una significación e influencia nacional y regional así como desarrollan una capacidad de interpelación y articulación con sectores sociales urbanos en la confrontación con el régimen neoliberal resulta el hecho más conocido de estas experiencias. La importancia alcanzada por estos movimientos de base territorial, sin embargo, está lejos de significar la desaparición del conflicto de los trabajadores asalariados urbanos. No solamente porque en muchos de estos movimientos puede distinguirse la presencia de trabajadores en las difusas y heterogéneas formas que esta categoría asume bajo el neoliberalismo que resulta en procesos de "reidentificación en términos no vinculados a la relación entre capital y trabajo, sino en otros muy distintos, entre los cuales los criterios de 'pobreza' de 'etnicidad', de oficios y de actividades 'informales' y de comunidades primarias son, probablemente, los más frecuentes" (Quijano, 2004). En el terreno del conflicto de los trabajadores ocupados puede señalarse el crecimiento de aquellos protagonizados por los asalariados del sector público en desmedro de los impulsados por los del sector privado de la economía. Este hecho implica, a su vez, una configuración particular que atraviesa la acción de las organizaciones sindicales en tanto la dinámica reivindicativa en muchos casos trasciende sus contenidos corporativos para convocar a la participación y convergencia con otros sectores sociales en la defensa del carácter público, la calidad y universalización del acceso a ciertos servicios sociales (particularmente la educación y la salud). ${ }^{2}$ 
En relación a las formas de lucha es importante destacar la generalización de medidas confrontativas en desmedro de las demostrativas, que se expresa también en la difusión regional de ciertas modalidades como los bloqueos de carreteras (característicos por ejemplo de la protesta de los movimientos de trabajadores desocupados en Argentina como de los movimientos indígenas y cocaleros del Área Andina), las ocupaciones de tierras y viviendas o de edificios públicos. Por otra parte, la recurrencia de largas marchas que atraviesan durante días y semanas los espacios regionales y nacionales parecen querer contrarrestar la dinámica de segmentación socio-territorial promovida por el neoliberalismo; así como las puebladas y levantamientos urbanos aparecen como estrategias tendientes a la reapropiación colectiva de lo político-público. Estos breves señalamientos deben complementarse con tres elementos que con distintas formas e intensidades parecen atravesar la práctica constitutiva de la mayoría de los más significativos movimientos sociales latinoamericanos.

En primer lugar, una dinámica de apropiación territorial que caracteriza la práctica colectiva de estos movimientos. Presentada como "la respuesta estratégica de los pobres a la crisis de la vieja territorialidad de la fábrica y la hacienda... [y a] la desterritorialización productiva... [impulsada por] las contrarreformas neoliberales" (Zibechi, 2003) así como al proceso de privatización de lo público y la política (Boron, 2003) esta tendencia a la reapropiación comunitaria del espacio de vida refiere tanto a las formas de lucha y organización basadas en la ocupación del territorio cuanto a la expansión de las experiencias de autogestión productiva, de resolución colectiva de necesidades sociales (por ejemplo en el terreno de la educación y la salud) y de formas autónomas de gestión de los asuntos públicos. En este continum diverso pueden abarcarse los asentamientos cooperativos del MST brasileño, las comunidades indígenas en Ecuador y Bolivia, los municipios autónomos zapatistas en México, los emprendimientos productivos de los diferentes movimientos de desocupados y el movimiento de fábricas recuperadas ambos en Argentina, así como las puebladas y levantamientos urbanos que 
implicaron la emergencia de prácticas de gestión del espacio público (tal es el caso, por ejemplo, tanto de la "Guerra del Agua" en Cochabamba como del levantamiento de la ciudad de El Alto durante la "Guerra del Gas" en Bolivia, o la experiencia de las asambleas populares surgidas en los principales centros urbanos de Argentina a posteriori de diciembre de 2001 y de Ecuador - centrado en Quito en abril de 2005). En tensión permanente con el mercado y el Estado, extendidas en el tiempo o inestables y temporarias, asentadas en prácticas de producción y reproducción de la vida u operando simplemente en el terreno de la gestión de lo público-político, esta dinámica de reapropiación colectiva del territorio social parece orientar la experiencia no sólo de los movimientos indígenas y campesinos sino también en el espacio urbano.

En segundo lugar, y en consonancia con lo referido anteriormente, la práctica y la discursividad de la mayoría de los movimientos sociales aparece atravesada por una intensa experimentación democrática que implica tanto la reinvención como revalorización de mecanismos de participación y decisión directos o semidirectos y que orientan tanto los modelos organizativos de matriz asamblearia como las programáticas, demandas y cuestionamientos al Estado-nación y al régimen de "democracia representativa de baja intensidad" forjado bajo el imperio del neoliberalismo. Desde la voz zapatista del mandar obedeciendo hasta las consultas populares (y las demanda de plebiscitos vinculantes) adoptados por las campañas nacionales contra los tratados de libre comercio esta experimentación democrática se expresa en la búsqueda de formas participativas más horizontales y de control de la delegación como en una dinámica de confrontación y democratización de la gestión de lo público en una diversidad de demandas que van desde las formas de la democracia participativa a los reclamos y construcción de autonomía y autogobierno territorial.

En tercer y último lugar vale señalar la emergencia de un nuevo internacionalismo que ha teñido de manera profunda y singular la experimentación de los movimientos sociales tanto a nivel continental como mundial. El carácter eminentemente social de los actores 
involucrados (aunque no desligado, por si hiciera falta la aclaración, de inscripciones ideológico-políticas), su heterogeneidad y amplitud, la extensión verdaderamente internacional de las convergencias, las formas organizativas y las características que asumen estas articulaciones señalan la novedad de este internacionalismo (Seoane y Taddei, 2001). Un recorrido por su genealogía nos conduce a las protestas contra el Acuerdo Multilateral de Inversiones (AMI, 1997/ 8), la "batalla de Seattle" que frustró la bautizada Ronda del Milenio de la Organización Mundial del Comercio (1999), la creación y profundización de la experiencia del Foro Social Mundial (FSM, 2001 al 2006) y las "jornadas globales" contra la intervención militar en Irak (2003/2004), y el surgimiento y desarrollo de las campañas contra el libre comercio y la guerra que tienen en la oposición al proyecto estadounidense del ALCA (Área de Libre Comercio de las Américas) y los tratados plurilaterales su capítulo americano más significativo (entre otras experiencias los Encuentros Hemisféricos de Lucha contra el ALCA, La Habana, Cuba, 2002 a 2005; y las Cumbres de los Pueblos en oposición de las Cumbres de Presidentes de las Américas).

\section{De la lucha por la tierra a la defensa del territorio y la vida}

En la experiencia de estos movimientos territoriales la lucha por la tierra aparece transformada en la concepción de territorio bajo su ocupación y defensa. Ciertamente en este desplazamiento le ha cabido un papel importante a la experiencia de los movimientos indígenas y su influencia sobre el conjunto de los actores sociales. Para ellos, como lo señalaba la dirigente de la CONAIE (Confederación de Nacionalidades Indígenas del Ecuador) Blanca Chancoso "la tierra significa como la madre...no solamente como fuente de trabajo sino la tierra como fuente de vida" (Chancoso, 2003). Así también es reconceptualizada en muchos de los movimientos campesinos la reforma agraria que, trascendiendo la mera distribución de tierra, implica un modelo de desarrollo agrícola alternativo al planteado por el agro-business. 
En la emergencia de los movimientos, organizaciones y conflictos sociales habitualmente nominados como de defensa de los recursos naturales aparece también la noción del territorio como "lugar donde la sustentabilidad se enraiza en bases ecológicas", en formulaciones alternativas de la relación entre la humanidad y la naturaleza y de la organización societal. Por otra parte, como la confrontación con la racionalidad económica productivista ha implicado en la experiencia de los movimientos sociales la crítica al concepto de "recursos naturales" y la nominación de los mismos como "bienes comunes"; la dinámica de los conflictos y las campañas contra la apropiación privada de los mismos y sus consecuencias catastróficas sobre la vida en el planeta han promovido también una programática signada por la defensa del territorio a la que se agrega la referencia de "defensa de la vida". Ejemplo de ello es que la consigna "si a la vida" forma parte hoy de la mayoría de las convergencias y articulaciones nacionales y regionales contra los tratados de libre comercio. Si bien en ello ha contribuido también la particular imbricación de sectores de diversas instituciones religiosas (especialmente de la iglesia católica) con dichos movimientos y campañas, en su profundidad ha respondido a la características asumidas por el proceso capitalista actual que pone en riesgo la propia supervivencia y amenaza la vida del planeta en todas sus formas, sea bajo la forma de la catástrofe ecológica, por la promoción de la militarización y la guerra como diagrama social o por la privación de las condiciones mínimas de la subsistencia.

\section{De las resistencias a las privatizaciones a la defensa de los bienes comunes}

La implementación del modelo neoliberal en nuestra América Latina y Caribeña a lo largo de la década de los '90 enfrentó, como señalamos en otra oportunidad, diversas resistencias y conflictos. $\mathrm{Si}$ bien las mismas en términos regionales no pudieron impedir la aplicación del recetario promovido por el "Consenso de Washington", en algunos casos nacionales o sectoriales las "contrarreformas 
neoliberales" se vieron obstaculizadas o ralentizadas. Esta situación en general se verificó en el terreno de las políticas privatizadoras en algunos sectores o países, particularmente donde la defensa de lo público convocó a un arco social amplio (involucrando un espacio que trascendía a los trabajadores del sector) y/o donde no hubo homogeneidad en el terreno del bloque dominante. Un ejemplo de ello fue ciertamente el proceso vivido en Uruguay, desde el triunfo en el referéndum de 1992 que frenó la Ley de Empresas Públicas promovida por el gobierno de Lacalle, al del 2004 (coincidente con las elecciones que dieron el triunfo a la coalición encabezada por el Frente Amplio) que se expresó mayoritariamente contrario a la privatización del servicio de agua. ${ }^{3}$

Sin embargo en la medida que el modelo neoliberal se tornó hegemónico en la región a lo largo de la década de los noventa, los procesos de privatización y mercantilización se extendieron más allá de la tradicional estructura de empresas y servicios públicos-estatales a un cada vez más amplio terreno societal signado por lo que algunos autores han llamado acumulación por desposesión (Harvey, 2004). Así, si la primera generación del concepto de privatización se enfocó sobre los activos del Estado y la segunda a los servicios, la tercera se orienta particularmente sobre los recursos naturales y estratégicos (Castro Soto, 2005b).

Estos procesos supusieron la emergencia de un conjunto de conflictos, entramados organizativos y articulaciones sociales, formas de lucha y programáticas vinculadas a la defensa de los bienes comunes naturales. De las luchas contra la explotación minera a la defensa de la biodiversidad, de la confrontación con la expansión del agro-business a la recreación de formas alternativas de producción agrícola y la defensa de bosques y selvas, de las resistencias a la privatización de los servicios de agua al movimiento contra las represas y defensa de las reservas acuíferas, de los conflictos contra la privatización de las empresas petroleras estatales al cuestionamiento de la explotación petrolera y la disputa por la distribución y apropiación de los beneficios, de la lucha por la tierra a la defensa de la producción de coca y el surgimiento de los llamados movimientos cocaleros, etc. 
En ellos puede vislumbrarse la territorialización de los movimientos sociales, la experimentación democrática y la nervadura del nuevo internacionalismo.

\section{No a la minería: la experiencia de Conacami en Perú}

Organizaciones, resistencias y protestas se extienden y recorren todo el cinturón de sierras y montañas latinoamericanas frente a la explotación minera. En toda mesoamérica, especialmente en Guatemala, en Chile, en Argentina (ver texto de Cotarelo y Declaración del reciente III Encuentro de Comunidades Afectadas por la Minería de la Argentina), en Perú, el "No a las minas" despierta movilizaciones y conflictos. En este caso, queremos detenernos brevemente en la presentación de la experiencia en este último país.

A lo largo de la década del noventa y en el marco de las políticas de desregulación, de privatización e incremento de inversiones extranjeras, la actividad minera en Perú - orientada a la exportación - se incrementó significativamente llegando a sextuplicarse la superficie destinada a estos emprendimientos. Entre 1992 y 2002 el PBI correspondiente al sector minero así como las exportaciones mineras más que se duplicaron (Zavalla, 2004) siendo que las mismas cumplieron un papel particularmente relevante en la recuperación de las tasas de crecimiento económico a partir de 2003. Particularmente de plata y oro (sólo en peso de mineral extraído éstos representaron casi un tercio de lo producido en 2001) pero también de hierro, cobre, zinc, estaño y plomo. Las gravosas consecuencias (contaminación de ríos y tierra, desplazamientos) que dicha actividad descargó sobre las comunidades rurales y su pauperización - contrastante con el crecimiento de las ganancias empresarias - marcaron la persistente emergencia de protestas y conflictos que conllevaron a la creación de la Confederación de Comunidades Afectadas por la Minería (CONACAMI) entre 1999 y 2003. La CONACAMI abarca hoy a más de 1.600 comunidades rurales y urbanas de 18 regiones del Perú; sin ser declaradamente una organización indígena resulta uno de los agrupamientos más importantes de comunidades campesino-indígenas en este país. 
Por otra parte estos conflictos y protestas contra la explotación minera han crecido en el último período en el marco de un incremento de la movilización y las luchas sociales en el Perú (sobre ello pueden consultarse diferentes contribuciones incluidas en la bibliografía optativa). De aquellos acontecidos recientemente se desataca el protagonizado por comunidades de las provincias de Ayabaca y Huancabamba (Piura) contra el proyecto Río Blanco de la minera Majaz propiedad de la empresa inglesa Monterrico Metal. Dicho proyecto, destinado a la extracción de cobre y otros minerales, afecta las cuencas hidrográficas de la región, amenazando la vida y la actividad agrícola de las comunidades campesinas. Hacia fines de julio de 2005, comuneros de dichas provincias y de Jaén y San Ignacio (Cajamarca) iniciaron una masiva marcha hacia el campamento minero de Majaz exigiendo el retiro de la empresa y ser incluidos en la mesa técnica de diálogo convocada por el gobierno. Frustrados los intentos de establecer un diálogo ante la falta de voluntad gubernamental, el arribo de la marcha a las proximidades del campamento minero fue recibido por una violenta represión que el $1^{\circ}$ de agosto cobró trágicamente centenas de heridos y por lo menos un comunero muerto. Los conflictos se sucedieron en la zona, llegando los manifestantes a detener a trabajadores de la mina para evitar su funcionamiento, así como las poblaciones de las provincias de Huancabamba, Jaén y Ayabaca declararon un paro interregional (18/8). A pesar de ello la actividad de la empresa Majaz continúa al día de hoy. Según los registros de la CONACAMI existen actualmente en Perú 42 conflictos planteados alrededor de las explotaciones mineras, $7 \mathrm{de}$ los cuales pueden considerarse críticos (CONACAMI, 2005).

\section{El agua no es una mercancía}

"La próxima guerra mundial será por el agua" afirmaba el vicepresidente del Banco Mundial Ismael Serageldin a poco tiempo de distancia de la bautizada "guerra del agua" en Cochabamba, Bolivia (citado en Castro Soto, 2005). Pocos días atrás el Secretario de Defensa británico afirmaba que la emergencia de conflictos violentos 
por el agua y otros recursos naturales será cada vez más probable (Klare, 2006). ¿Cuál es la forma de la guerra a la que se refieren estas perspectivas? ¿Es el entramado de una "guerra" que va más allá de la figura de estados beligerantes y que se desplaza en la imposición de un diagrama de militarización del conflicto social?

La validez del pronóstico se afirma en la escasez del recurso. Sólo el 0,3\% del agua del planeta es apta para el consumo humano, siendo que más del $80 \%$ se concentra en los casquetes polares, los glaciares y la atmósfera. Sin embargo esta dinámica de apropiación y control militar de los recursos hídricos pareciera desprenderse como consecuencia de la lógica actual de mercantilización y apropiación privada de dicho recurso. En el marco de la mundialización neoliberal un complejo de corporaciones trasnacionales e instituciones internacionales aparece en el centro de este proceso de mercantilización del agua transmutada ahora en "oro azul". Como contraparte a ellos, la experiencia reciente de la acción colectiva de los movimientos populares ha fructificado en un conjunto diverso de coaliciones y coordinaciones tanto a nivel local, nacional, regional e internacional. Los mismos abarcan las luchas contra las reformas legislativas de privatización del servicio de aguas (entre las más significativas la "Guerra del agua" en Cochabamba) o por la desprivatización del mismo (nuevamente la experiencia boliviana con las movilizaciones que conllevaron la expulsión de la empresa concesionaria del servicio en la ciudad de El Alto resulta un ejemplo de ello) contra la contaminación y uso privado de las fuentes de agua (un ejemplo reciente de ello resulta el caso de las protestas y cortes del puente internacional en la ciudad argentina de Gualeyguaychú -y de otras ciudades de la misma provincia- frente a la instalación de dos grandes empresas de producción de pasta celulósica sobre la ribera uruguaya del compartido río Uruguay y el conflicto abierto entre los gobiernos de ambos países), contra la construcción de represas, ${ }^{4}$ y en defensa de las reservas acuíferas. ${ }^{5}$

El conjunto de estos conflictos y articulaciones sociales han enhebrado diferentes marcos de coordinación internacional en la medida que los procesos de mercantilización del agua aparecen 
consagrados y promovidos en los acuerdos supranacionales impulsados en diferentes organismos internacionales, especialmente en la OMC y el Foro Mundial del Agua cuya cuarta edición tuvo lugar recientemente en México. En este sentido, en el marco del proceso del Foro Social Mundial, una parte significativa de estos movimientos y coordinaciones nacionales y regionales emergidas en los últimos años en relación a la defensa del acceso y las fuentes de agua han dado vida a un espacio internacional de coordinación que toma como bandera principal la demanda de considerar el agua como un "derecho humano" que no puede someterse a la lógica del mercado y del lucro.

\section{La batalla por el gas en Bolivia}

El conflicto social por los bienes comunes, particularmente centrado alrededor de los hidrocarburos, habrá de asumir particularmente en la experiencia de la región Andina de los últimos años- una creciente proyección política nacional. En más de un sentido, la experiencia venezolana reciente resulta un ejemplo de ello, baste referir al ciclo de movilizaciones, intento de golpe de estado y lock-out patronal que confrontó, entre otras cuestiones, a la política petrolera y la reforma de la empresa estatal promovida por el gobierno del presidente Chávez, así como el papel que cumple en el desarrollo de la política social (particularmente las llamadas "misiones") de dicho gobierno la apropiación pública de la renta petrolera. En el caso de Bolivia, particularmente a partir de la "Guerra del Gas" (2003), la disputa social por la propiedad y distribución de los beneficios obtenidos de la explotación de la riqueza hidrocarburífera se ha transformado también y de manera creciente en el centro de la lucha política, articulándose a su alrededor las diferentes fuerzas y coaliciones sociales.

Las jornadas de octubre de 2003 se inscriben en un período de incremento del conflicto social y emergencia y consolidación de movimientos populares iniciado con la llamada "Guerra del Agua" 
(Cochabamba, 2000) que frustró la tentativa de privatización del servicio y las fuentes de agua de la región y marcó el reinicio de una nueva fase de protesta y movilización social antineoliberal bajo nuevas configuraciones luego del golpe sufrido por el proletariado minero y la declinación de la Central Obrera Boliviana (COB) a partir de 1985. El ciclo de conflicto y movilizaciones iniciado en el 2000 hubo de encontrar en el levantamiento popular de la ciudad de El Alto y en la demanda de nacionalización de los hidrocarburos un epicentro de articulación político-social de carácter nacional, prolongado luego en la exigencia de renuncia del presidente. Las memorias de enajenaciones y luchas pasadas; la indígena-katarista de la colonización española del oro y la plata, la del nacionalismo revolucionario del proletariado minero y el estaño; se condensaron en el presente de la batalla por el gas (Prada, 2003). Así la agenda de los movimientos sociales surgida en 2003 colocó la disputa por los hidrocarburos en el centro político nacional, cuya prolongación - no sin tensiones - se extiende hasta la masiva participación popular que selló el triunfo de la candidatura presidencial de Evo Morales, abriendo un nuevo escenario que cierra un ciclo signado por la creciente capacidad destituyente de los movimientos populares - que conllevó la caída de los gobiernos de Sánchez de Lozada (2003) y Carlos Mesa (2005) - y la persistente continuidad de la dominancia neoliberal, y que algunos análisis refirieran como una situación de empate. ${ }^{6}$

Lamentablemente no contamos con la posibilidad de extendernos sobre este proceso pero vale si resaltar que las elecciones del pasado 18 de diciembre resultan, desde distintos puntos de vista, un hecho de proporciones históricas en el terreno de la democratización societal de la sociedad boliviana señalado por la elección del primer presidente indígena (en una sociedad mayoritariamente indígena caracterizada por un régimen colonial de poder) que obtiene - contra la preferencia de las élites y el gobierno norteamericano - un apoyo popular inédito en la reciente historia de la democracia representativa en Bolivia, y en el marco de una participación electoral desconocida en las últimas décadas. Su significación nacional y regional y la demanda sobre la propiedad y apropiación pública de las riquezas hidrocarburíferas señalan la 
magnitud de los desafíos planteados, en particular frente a los poderosos intereses involucrados en la defensa de la matriz neoliberal.

\section{A modo de conclusión}

La irrupción en la ciudadela de la gobernabilidad política neoliberal de los sectores sociales más castigados por la aplicación de este recetario (campesinos e indígenas, los sin trabajo y sin tierra, los trabajadores y sectores urbanos empobrecidos) no sólo abrió nuevos horizontes de futuro - agrietando la hegemonía del pensamiento único - sino que significó también el desarrollo de una intensa experimentación democrática, de reconstitución de alternativas societales, de reapropiación social de los público y de actualización de las posibilidades de una transformación "posneoliberal" de las sociedades latinoamericanas y caribeñas. Estos procesos estuvieron a la base del triunfo electoral de coaliciones político-partidarias inspiradas en una programática y discursividad crítica del neoliberalismo.

Por otra parte el regreso del crecimiento económico a nivel regional a partir de 2004 - basado principalmente en el dinamismo de las exportaciones de materias primas y commodities - y el impulso de los acuerdos de librecomercio - que legalizan y acentúan esta matriz societal - parecieran querer exorcizar estas aspiraciones de cambio resucitando la ilusión de la progresiva, pero segura, difusión social de la riqueza. En este contexto la continuidad de la protesta social y la reconceptualización democrática de la política como posibilidad de transformación contrasta también con las iniciativas de las élites tendientes a limitar institucionalmente las demandas sociales, a acentuar y expandir un diagrama de militarización social y a disputar el espacio de la movilización callejera. Tanto por el lugar que les cabe en la dinámica del modelo neoliberal cuanto por su papel en la gestación de resistencias y alternativas, la disputa por los bienes 
comunes de la naturaleza asume un lugar significativo en esta confrontación social.

La dinámica de ocupación, disputa y defensa del territorio aparece de manera explícita en las formas de acción colectiva y de lucha desplegadas por los colectivos y movimientos sociales abordados, forjando una ilegalidad democrática para usar la expresión de Boaventura de Sousa Santos. El surgimiento de modelos organizativos amplios y participativos - sea bajo la forma asamblea o la forma coordinadora -, el uso de medidas de lucha basadas en la movilización comunitaria, y la búsqueda de una democratización de la gestión pública reseñan un conjunto de experiencias orientadas hacia una recreación participativa y radical de la democracia. En esta dirección podríamos afirmar que "la política antineoliberal pareciera encaminarse en una acción de [...] reproducción y producción de sociedad más allá de la producción ampliada y dislocada de los capitales transnacionales" (Tapia, 2000).

Por otra parte la activa participación de organizaciones o grupos ecologistas y/o ambientalistas y su articulación con las comunidades afectadas (que ofrece en muchos casos una capacidad de difusión y articulación con las redes internacionales) señala también la medida en que las cosmovisiones respecto de la relación entre sociedad y naturaleza de los pueblos originarios y las comunidades campesinas se entrelazan con las problemáticas contemporáneas de la ecología política que cuestiona las visiones de un desarrollismo productivista. La confrontación con el modelo neoliberal que basado en la expansión espacial y social de la racionalidad económica y las leyes del mercado exaspera el tradicional carácter predatorio y destructor de la naturaleza y de las condiciones de vida del capitalismo ha significado la corporeización de una "racionalidad ambiental internalizada (y recreada) por nuevos actores sociales, expresándose como una demanda política que guía nuevos principios para la valoración del ambiente y para la reapropiación de la naturaleza" (Leff, 2005).

Por otra parte la defensa del carácter de bien común de los recursos naturales ha devenido en un elemento importante de la articulación político-nacional de los movimientos populares y en la 
polarización socio-política; así como la apropiación pública de los beneficios resultado de su explotación puede jugar un papel significativo en el camino de ruptura del modelo neoliberal. Ello ciertamente no oculta la siempre latente tensión entre las demandas ligadas a las consecuencias ambientales y aquellas surgidas del cuestionamiento a la apropiación privada de los bienes comunes naturales así como con la supervivencia o recreación de un neodesarrollismo productivista. En relación a ello es necesario señalar también que la dinámica de los conflictos en defensa de los bienes comunes se ve confrontada, en muchas ocasiones, con otras acciones colectivas orientadas a la defensa de los emprendimientos cuestionados y protagonizadas por los trabajadores ocupados por los mismos, estimuladas muchas veces por las corporaciones empresarias o por la expectativa del prometido beneficio del empleo o el desarrollo regional.

Un hilo conductor recorre la programática de estos conflictos: la defensa del carácter público-comunitario de estos bienes y la desmercantilización de los mismos; programática que referida inicialmente a su uso social se desplaza también a los terrenos de la gestión y propiedad. Finalmente en razón de la raíz internacional de las corporaciones empresariales y las estrategias y procesos orientados a la mercantilización de los bienes comunes, las experiencias forjadas a nivel local o nacional por los propios movimientos sociales han tendido a construir rápidamente vínculos más allá del espacio nacional, constituyéndose en muchos casos en parte importante de las campañas contra el libre comercio y la militarización y jugando un papel en lo que ha dado en llamarse "movimiento altermundialista".

Estas experiencias de resistencia, postulación de horizontes emancipatorios y configuración de alternativas - con sus complejidades, tensiones y desafíos - enfrentan la dinámica y características que asumen hoy la ola de libre comercio y los procesos de militarización social que la acompañan así como las nuevas formas que adopta la gobernabilidad neoliberal. En esa contraposición se entretejen los desafíos presentes y futuros de hacer esa "Otra América" que tanto reclaman nuestros pueblos. 


\section{Notas}

1 El OSAL realiza y coordina desde el año 2000 un esfuerzo regional que abarca la participación de diferentes investigadores y centros de investigación - dedicado al seguimiento del conflicto social que, a partir de la consulta cotidiana de más de 80 fuentes, fructifica, entre otras cuestiones, en la elaboración de cronologías de la protesta social que se publican regularmente en la revista del Programa. Los países considerados en el relevamiento de los hechos de conflicto son: Argentina, Brasil, Bolivia, Chile, Colombia, Costa Rica, Ecuador, El Salvador, Guatemala, Honduras, México, Nicaragua, Panamá, Paraguay, Perú, Puerto Rico, República Dominica, Uruguay y Venezuela.

2 En este sentido es importante marcar que, en muchos casos, las luchas contra estas políticas de desmantelamiento y privatización, el impulso de los procesos de convergencia - que adoptan las formas de coordinadoras y frentes cívicos - no necesariamente reposa sobre la dinámica sindical asalariada, destacándose la importancia del papel jugado por otras organizaciones (movimientos campesinos, indígenas, desocupados, estudiantes, movimientos urbanos, entre otros) en la conformación de estas "coaliciones sociales amplias".

3 De la geografía regional de estas luchas se destacan, además de las referidas en Uruguay, las acontecidas en Paraguay (en un ciclo de convergencias y conflictos que se prolonga hasta hoy), en Bolivia (de la derrota del intento de privatización del agua en Cochabamaba en 2000 a la expulsión de la empresa que detentaba la gestión de dicho recurso en El Alto en 2005), en Perú (en relación con la privatización de empresas públicas regionales, particularmente nos referimos a la experiencia de Arequipa en 2003 que detuvo la privatización de la empresa eléctrica local) y hasta el tiempo presente las luchas contra las privatizaciones pretendidas por el presidente Fox en México (particularmente en el sector eléctrico, telefónico y petrolero) y las masivas manifestaciones iniciadas frente a Mireya Moscoso y prolongadas en el actual gobierno de Omar Torrijos frente al proyecto de privatización de la Caja del Seguro Social en Panamá.

4 En la región latinoamericana, se destaca la experiencia del Movimiento dos Atingidos por Barragens (MAB) en Brasil, surgido en 1989 cuando, en el marco del primer encuentro nacional de trabajadores damnificados por la construcción de represas, se decidió la construcción de una organización más fuerte a nivel nacional. El MAB es un movimiento de proyección nacional, con fuertes articulaciones con el MST. 
5 De las reservas acuíferas de la región latinoamericana una de las más importantes es el Acuífero Guaraní. Considerada por algunos como el yacimiento subterráneo de agua dulce más grande del planeta, sus reservas se estiman en $40 \mathrm{mil} \mathrm{km}^{3}$ siendo que se extiende bajo el territorio de Brasil (70\%), Argentina (19\%), Paraguay (6\%) y Uruguay (5\%) (Ceceña y Motto: 2005). El carácter transfonterizo de dicha reserva ha motivado espacios de coordinación subregional orientados a su defensa y en rechazo a la militarización de la zona, entre otros el Foro Social de la Triple Frontera, cuya primera edición sesionó a mediados de 2004 en Iguazú (Misiones, Argentina).

6 La caracterización de la situación como de "empate catastrófico", retomando la formulación de Antonio Gramsci, fue utilizada por numerosos analistas e investigadores para referirse al proceso boliviano abierto desde 2003. También bajo inspiración gramsciana, se ha caracterizado al período iniciado en 2000 como una "guerra de posiciones contra el neoliberalismo" (Tapia, 2005).

\title{
Social movements and the defense of natural resources in Latin America: reaction against the neoliberal model and the construction of alternatives
}

\begin{abstract}
The imposition of the neoliberal model in Latin America and the Caribbean as well as the recent return to economic growth in the region are mainly due to the massive exploitation of natural resources geared to exports and which, to a large extent, are controlled by transnational capital. As a result, a growing number of conflicts, social movements and sociopolitical consensus building have emerged and developed in the continent on local, national and regional levels. These efforts are part of a new cycle of social protest that arose in the second half of the 1990s. The main features that represent the current makeup of the collective organization and action of today's social movements can be glimpsed in those experiences. In this sense, the defense of natural resources as a common good has been expressed in the social reaction against the devastation of the environment, the destruction of habitats and the forced displacement of peoples. It has also been raised in questions regarding the impact and the model of private appropriation of these resources and the benefits derived from exploiting them. In the field of social movements, the articulation of these processes has meant linking the cycle of resistance to the construction of alternatives and the positing of liberating horizons.
\end{abstract}


Key-words: social movements, conflicts, social protests, natural resources, neoliberalism

\section{Referencias bibliográficas}

BORON, Atilio. Estado, capitalismo y democracia en América Latina. Buenos Aires: CLACSO, 2003.

CASTRO SOTO, Gustavo. El movimiento social en Mesoamérica por la defensa de los recursos naturales. OSAL, Buenos Aires, v.6, n.17, mayo/ago. 2005. Disponible en: <http://osal.clacso.org/espanol/html/ frevista.html>.

El marco global del movimiento mesoamericano contra la privatización de los recursos naturales. 2005b. Mimeogr.

CECEÑA, Ana Esther. Revuelta y territorialidad. Actuel Marx, Argentina, $\mathrm{n}$. 3, nov. 2000. p. 111-120.

CECEÑA, Ana Esther; MOTTO, Carlos Ernesto. Paraguay: eje de la dominación del Cono Sur. OSAL, Buenos Aires, v. 6, n. 17, mayo/ago. 2005. Disponible en: <http://osal.clacso.org/espanol/html/ frevista.html>.

CHANCOSO, Blanca. Exposición en el Panel 5: "Movimientos sociales: entre la crisis del neoliberalismo y el desafío de las alternativas", en la XXI Asamblea General de CLACSO, La Habana, Cuba, 2003.

CONACAMI. Los conflictos mineros se agudizan y el gobierno incumple creación de comisión de Diálogo de Alto Nivel; comunicado de CONACAMI, Lima, Perú, 25 de julio de 2005. OSAL, Buenos Aires, v. 6, n. 17, mayo/ago. 2005. Disponible en: <http://osal.clacso.org/ espanol/html/frevista.html>.

DECLARACIÓN conjunta de los movimientos y organizaciones sociales sobre el agua. In: Foro Social Mundial, 6. Caracas, Venezuela. [Anais...]. 2006.

GALEANO, Eduardo. Las venas abiertas de América Latina. Buenos Aires: Catálogos, 2002.

HARVEY, David. El nuevo imperialismo. Madrid: AKAL, 2004.

KLARE, Michael. Se avecinan guerras por los recursos. Diario La Jornada, México, 19 marzo 2006. 
LANDER, Edgardo. ¿Modelos alternativos de integración? Proyectos neoliberales y resistencias populares. OSAL. Buenos Aires, v. 5, n. 15, sep./dic. 2004. Disponible en: <http://osal.clacso.org/espanol/ $\mathrm{html} /$ frevista.html .

LEFF, Enrique. La geopolítica de la biodiversidad y el desarrollo sustentable. OSAL, Buenos Aires, v. 6, n. 17, mayo/ago. 2005. Disponible en: <http://osal.clacso.org/espanol/html/frevista.html>.

OSAL. Informe sobre la evolución de la conflictividad social en América Latina y el Caribe. Buenos Aires: Observatorio Social de América Latina (OSAL), CLACSO, 2005. Mimeogr.

MANÇANO FERNANDES, Bernardo. Movimentos socioterritoriais e movimentos socioespaciais. OSAL, Buenos Aires, v. 6, n. 16, ene./ abr. 2005. Disponible en: <http://osal.clacso.org/espanol/html/ frevista.html>.

PAJUELO TEVES, Ramón. Perú: crisis política permanente y nuevas protestas sociales. OSAL, Buenos Aires, v. 5, n. 14, mayo/ago. 2004. Disponible en: <http://osal.clacso.org/espanol/html/frevista.html〉.

PRADAALCOREZA, Raúl. Perfiles del movimiento social contemporáneo: el conflicto social y político en Bolivia. OSAL, Buenos Aires, v. 4, n. 12, sep./dic.2003. Disponible en: <http://osal.clacso.org/espanol/ $\mathrm{html} /$ frevista.html>.

QUIJANO, Aníbal. El laberinto de América Latina ¿hay otras salidas? OSAL, Buenos Aires, v. 5, n. 13, ene./abr. 2004. Disponible en: <http:// osal.clacso.org/espanol/html/frevista.html>.

SEOANE, José. Movimientos sociales y recursos naturales: resistencias al neoliberalismo y configuración de alternativas. OSAL, Buenos Aires, v. 6, n. 17, mayo/ago. 2005. Disponible en: <http://osal.clacso.org/ espanol/html/frevista.html>.

SEOANE, José; TADDEI, Emilio. De Seattle a Porto Alegre: pasado, presente y futuro del movimiento antimundialización neoliberal. In: SEOANE, J.; TADDEI, E. (comp.). Resistencias mundiales, de Seattle a Porto Alegre. Buenos Aires: CLACSO, 2001.

SEOANE, José; TADDEI, Emilio; ALGRANATI, Clara. The new configurations of popular movements in Latin America. In: BORON, A.; LECHINI, G. (Comp.). Politics and social movements in an hegemonic world. Buenos Aires: CLACSO, 2005. 
TAPIA, Luis. La crisis política de abril. OSAL, Buenos Aires, n. 2, sep. 2000. Disponible en: <http://osal.clacso.org/espanol/html/frevista.html>. La cuarta derrota del neoliberalismo en Bolivia. OSAL, Buenos Aires, v. 6, n. 17, mayo/ago. 2005. Disponible en: <http:// osal.clacso.org/espanol/html/frevista.html>.

ZAVALLA, Cynthia. Canon minero y distribución de ingresos en el Perú. In: PERÚ hoy: los mil días de Toledo. Lima: DESCO, 2004.

ZIBECHI, Raúl. Los movimiento sociales latinoamericanos: tendencias y desafíos. OSAL, Buenos Aires, n. 9, ene. 2003. Disponible en: <http:/ /osal.clacso.org/espanol/html/frevista.html>. 